\title{
MINIESTAQUIA DE Eucalyptus benthamii: EFEITO DO GENÓTIPO, AIB, ZINCO, BORO E COLETAS DE BROTAÇÕES
}

\author{
Gilvano Ebling Brondani ${ }^{*}$, Francisco José Benedini Baccarin², Tábata Bergonci², Antonio Natal Gonçalves², \\ Marcilio de Almeida
}

*Autor para correspondência: gebrondani@yahoo.com.br

\begin{abstract}
RESUMO: Objetivou-se avaliar o enraizamento adventício em miniestacas de Eucalyptus benthamii em relação ao genótipo, concentrações de $\mathrm{Zn}$ e B, coleta de brotações e aplicação de AIB. As brotações foram oriundas de minicepas fertirrigadas com soluções nutritivas variando nas concentrações de Zn e B (S1 - isento de Zn e B, S2 - 0,5 mg L $\mathrm{L}^{-1}$ de Zn, S3 - 0,5 mg L-1 de B, S4 $0,5 \mathrm{mg} \mathrm{L}^{-1}$ de $\mathrm{Zn}$ e B, S5 - 1,0 $\mathrm{mg} \mathrm{L}^{-1}$ de Zn e B, S6 - 2,0 $\mathrm{mg} \mathrm{L}^{-1}$ de Zn e B). A região basal da miniestaca foi imersa durante $10 \mathrm{~s}$ em solução contendo $2.000 \mathrm{mg} \mathrm{L}^{-1}$ de AIB, sendo uma solução isenta de AIB utilizada como controle. Avaliaram-se a sobrevivência das miniestacas na saída da casa de vegetação, na saída da casa de sombra e em área de pleno sol. Em área de pleno sol foram avaliadas apenas as miniestacas enraizadas, e destas, o comprimento total do sistema radicial. O enraizamento adventício em miniestacas de Eucalyptus benthamii dependeu do material genético, da coleta de brotações, da aplicação de AIB e das concentrações de Zn e B. A porcentagem de enraizamento foi baixa, sendo que os materiais genéticos foram considerados de difícil propagação pela miniestaquia.

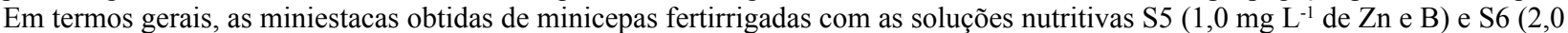
$\mathrm{mg} \mathrm{L}^{-1}$ de Zn e B) associadas a presença de AIB na concentração de $2.000 \mathrm{mg} \mathrm{L}^{-1}$ apresentaram os maiores índices de enraizamento.
\end{abstract}

Palavras-chave: Miniestaquia, rizogênese, clonagem, ácido indolbutírico.

\section{MINI-CUTTING OF Eucalyptus benthamii: EFFECT OF THE GENOTYPE, IBA, ZINC, BORON AND SHOOTS COLLECTION}

\begin{abstract}
The aim of this study was to evaluate the induction of adventitious rooting in Eucalyptus benthamii mini-cuttings regarding to genotype, $Z n$ and $B$ concentrations, shoot collections and IBA application. Shoots for the mini-cuttings confection were collected from mini-stumps fertigated with nutrient solutions containing different concentrations of $Z n$ and $B$ (S1-free of $Z n$

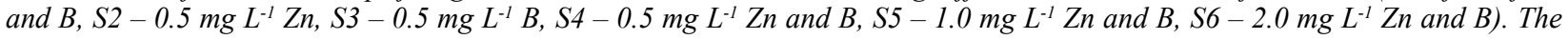
basal portion of the mini-cuttings was immersed for $10 \mathrm{~s}$ in a solution containing 2,000 $\mathrm{mg} \mathrm{L}^{-1} \mathrm{IBA}$. A free IBA solution was used as control. The mini-cuttings survival in greenhouse, shade-house and in full sun area were evaluated. In full sun area, only the rooted mini-cuttings were evaluated, and of these, the total length of the root system was measured. The adventitious rooting of Eucalyptus benthamii mini-cuttings depended of the genotype, $Z n$ and B concentrations, shoots collections and IBA application. In general, the adventitious rooting percentage was low, and the genotypes were considered difficult to propagation by mini-cuttings technique. The mini-cuttings collected of mini-stumps fertigated with nutrient solutions $S 5$ (1.0 $\mathrm{mg} \mathrm{L}^{-1} \mathrm{Zn}$ and B) and S6 (2.0 $\mathrm{mg} \mathrm{L}^{-1} \mathrm{Zn}$ and $B)$ associated with the presence of IBA in the concentration of 2,000 $\mathrm{mg} \mathrm{L}^{-1}$ presented the greater adventitious rooting percentage.
\end{abstract}

Key words: Mini-cutting technique, rhyzogenesis, cloning, indole-3-butyric acid.

\section{INTRODUÇ̃̃O}

A técnica de miniestaquia é a mais utilizada pelas grandes empresas florestais para a clonagem de genótipos selecionados de Eucalyptus, possibilitando consideráveis ganhos de produtividade decorrentes do aumento dos índices de enraizamento e da redução do tempo na formação da muda em comparação com a estaquia (ALFENAS et al., 2004). Contudo, existem espécies consideradas de difícil enraizamento, tal como o Eucalyptus benthamii (GRAÇA et al., 1999), que apesar de ser uma espécie de interesse para a composição de plantios florestais homogêneos em

${ }^{1}$ Universidade Federal de Mato Grosso - Cuiabá, Mato Grosso, Brasil

${ }^{2}$ Universidade de São Paulo - Piracicaba, São Paulo, Brasil regiões mais frias, ainda não existe protocolo eficiente para a obtenção em larga escala de mudas clonais.

Em sistemas de minijardins clonais os nutrientes são fornecidos, preferencialmente, por gotejamento a cada minicepa, regulando a vazão e concentração de nutrientes para garantir a produção de brotações com qualidade nutricional adequada (HIGASHI et al., 2002), sendo que o $\mathrm{Zn}$ e B são micronutrientes que se destacam em relação a rizogênese (CUNHA et al., 2009). Seguindo esse princípio, Cunha et al. (2005) avaliaram a produção e sobrevivência de minicepas de Eucalyptus benthamii conduzidas em sistemas de minijardins clonais em hidroponia e tubete. Os

Cerne, Lavras, v. 20, n. 1, p. 147-156, jul./set. 2014 
autores concluíram que ambos os tipos de manejo foram tecnicamente viáveis para a produção de brotações para a confecção de miniestacas durante todo o ano. Contudo, o efeito da composição da solução nutritiva em relação aos índices de enraizamento não foi avaliado. Higashi et al. (2002) salientam que não existe uma solução nutritiva padrão que possa ser aplicada para todas as espécies florestais em condições de cultivo intensivo, sendo que os nutrientes necessários para o desenvolvimento são os mesmos, porém as quantidades exigidas para cada espécie são diferenciadas.

Aplicações de fitorreguladores promovem efeitos positivos à rizogênese em espécies difíceis de enraizar, sendo que o ácido indolbutírico (AIB) é o mais utilizado (ALMEIDA et al., 2007; BRONDANI et al., 2010a; DIAS et al., 2012; TRUEMAN; ADKINS, 2013; WENDLING et al., 2000; WENDLING; XAVIER, 2005). As concentrações de AIB para induzir a rizogênese variam muito entre as espécies de Eucalyptus (ALMEIDA et al., 2007; BRONDANI et al., 2010a; BRONDANI et al., 2010b; CORREAA; FETT-NETO, 2004; TITON et al., 2003; WENDLING et al., 2000), sendo necessário estabelecer concentrações ideais de acordo com cada situação de manejo no viveiro e tipo de material genético. Com base no exposto, objetivou-se avaliar o enraizamento adventício em miniestacas de Eucalyptus benthamii em relação ao genótipo, coleta de brotações, aplicação de AIB e concentrações de Zn e B.

\section{MATERIAL E MÉTODOS}

\subsection{Constituição do minijardim clonal}

As unidades experimentais foram compostas por mudas clonais de Eucalyptus benthamii (clones BP101, BP118 e BP120) propagadas pelo processo de miniestaquia (ALFENAS et al., 2004) e cultivadas em vasos plásticos $(18 \times 16 \times 45 \mathrm{~cm})$ com duas aberturas na porção inferior (Figura $1 \mathrm{~A}$ ). O substrato foi composto por areia, fração fina $(0,10 \mathrm{~mm}<$ diâmetro de partícula $<0,25 \mathrm{~mm})$, o qual foi lavado com água deionizada por cinco vezes, seguido de autoclavagem durante 20 minutos a $121^{\circ} \mathrm{C}\left(\approx 1,0 \mathrm{kgf} \mathrm{cm}^{2}\right)$. Nos vasos foram plantadas seis mudas no espaçamento $10 \times 8 \mathrm{~cm}$, sendo duas mudas de cada clone dispostas sequencialmente. Após sete dias efetuou-se a quebra do caule das mudas a $10 \mathrm{~cm}$ acima da base com a finalidade induzir o crescimento de brotações axilares (Figura $1 \mathrm{~B}$ ), sendo realizada poda da parte aérea a $7 \mathrm{~cm}$ acima da base da muda para a formação da minicepa (Figura 1 C-D).

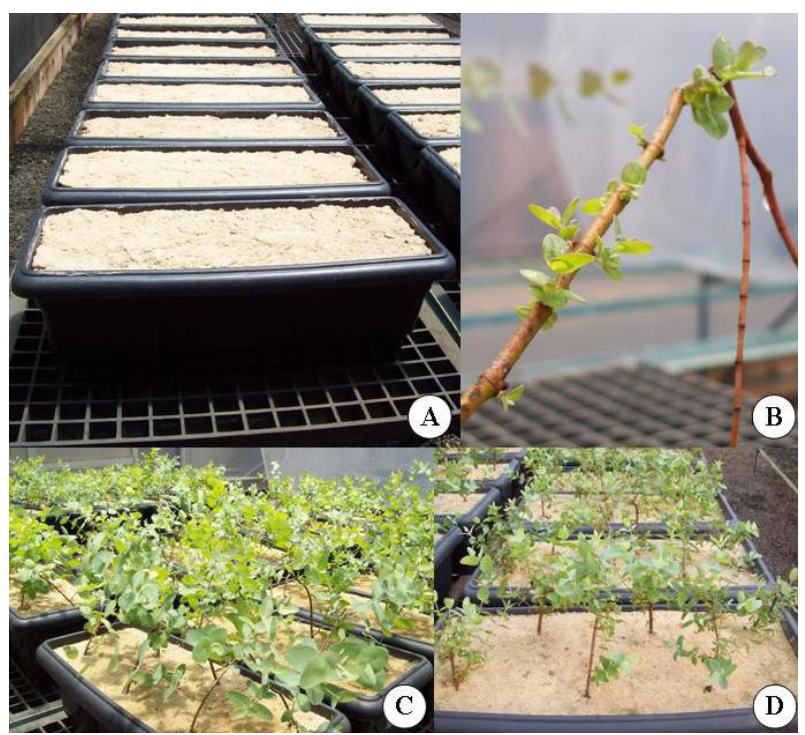

Figura 1 - Unidade experimental para a constituição do minijardim clonal de Eucalyptus benthamii. (A) detalhe do vaso contendo areia fina; (B) detalhe da indução de brotações axilares pela quebra do caule aos 21 dias; (C) disposição dos vasos contendo as minicepas aos 50 dias; (D) minicepas emitindo brotações aptas para a coleta aos 50 dias.

Figure 1 - Experimental unit for the establishment of clonal mini-garden of Eucalyptus benthamii. (A) detail of the recipient containing fine sand, (B) induction of axillary shoots by breaking of the stem, at 21 days, $(C)$ detail of recipient containing the mini-stumps, at 50 days, (D) mini-stumps emitting shoots able to collect, at 50 days.

\subsection{Manejo das minicepas}

O minijardim clonal foi instalado em condições de estufa recoberta com polietileno transparente e composta por dois sistemas de ventiladores. A cada sete dias adicionou-se $100 \mathrm{~mL}$ de solução nutritiva básica por minicepa (Tabela 1), sendo realizada irrigação com água deionizada diariamente. A cada semana foi realizada lavagem da areia com água deionizada para evitar a salinização.

\subsection{Coleta das brotações e preparo das miniestacas}

As miniestacas foram preparadas com um corte reto na região basal, mantendo-se o ápice, dois pares de folhas ( $50 \%$ da área total foliar) e dois pares de gemas sem as folhas na porção inferior, apresentando comprimento médio de $7 \mathrm{~cm}( \pm 2 \mathrm{~cm})$. 


\subsection{Variação de Zn e B na solução nutritiva}

Diferentes concentrações de zinco (Zn) e boro (B) foram fornecidas via solução nutritiva ( $\mathrm{S} 1$ - isento de $\mathrm{Zn}$ e B, S2 - 0,5 mg L L de Zn, S3 - 0,5 mg L-1 de B, S4 - 0,5 $\mathrm{mg} \mathrm{L}^{-1}$ de Zn e B, S5 - 1,0 $\mathrm{mg} \mathrm{L}^{-1}$ de Zn e B, S6 - 2,0 mg $\mathrm{L}^{-1}$ de $\mathrm{Zn}$ e $\mathrm{B}$ ). $\mathrm{O} \mathrm{Zn}$ foi fornecido na forma de sulfato de zinco $\left(\mathrm{ZnSO}_{4} .7 \mathrm{H}_{2} \mathrm{O} / 287,54\right)$ e o $\mathrm{B}$ foi fornecido na forma de ácido bórico $\left(\mathrm{H}_{3} \mathrm{BO}_{3} / 61,83\right)$.

\subsection{Aplicação de AIB}

A região basal da miniestaca foi imersa durante $10 \mathrm{~s}$ em solução hidroalcoólica (1:1, água:álcool, v/v) nas concentrações de 0 (isento de AIB) ou $2.000 \mathrm{mg} \mathrm{L}^{-1}$ de AIB. Ao longo do experimento avaliaram-se a sobrevivência das miniestacas na saída da casa de vegetação (SCV), na saída da casa de sombra (SCS) e em área de pleno sol (APS). Em área de pleno sol (APS) foram avaliadas apenas as miniestacas enraizadas, e destas, o comprimento total do sistema radicial (CTSR) a partir do software SIARCS (EMBRAPA, 1996).

\subsection{Condições de enraizamento}

As miniestacas foram inseridas a $2 \mathrm{~cm}$ de profundidade em substrato (vermiculita média e substrato a base de casca de pinus decomposta, 2:1, v/v) que foi distribuído em tubete cônico $\left(55 \mathrm{~cm}^{3}\right)$. As miniestacas permaneceram entre 35 a 42 dias em casa de vegetação automatizada com nebulização intermitente. Após, as miniestacas foram transferidas para casa de sombra (sombrite de $50 \%$ ), onde permaneceram por 14 a 21 dias. Após o processo de aclimatação, as miniestacas foram transferidas para uma área de pleno sol, visando a rustificação e crescimento por 30 dias. Da casa de sombra até a avaliação em área de pleno sol, as miniestacas receberam fertirrigação semanal $\left(2 \mathrm{~L} \mathrm{~m}^{-2}\right)$ com a solução nutritiva básica (Tabela 1), acrescida de $0,1 \mathrm{mg} \mathrm{L}^{-1}$ de $\mathrm{Zn}$ e $0,1 \mathrm{mg} \mathrm{L}^{-1} \mathrm{de} \mathrm{B}$. Os valores da temperatura do ar (máxima, média e mínima) foram coletados diariamente.

\subsection{Delineamento experimental e análise estatística dos dados}

O experimento foi conduzido no delineamento inteiramente casualizado em arranjo fatorial $(3 \times 8 \times 6 \times 2)$ com parcelas subdivididas no tempo, sendo os fatores constituídos por três clones, oito coletas de brotações, seis combinações de Zn e B, na ausência e presença de AIB, com cinco repetições de 10 a 20 miniestacas por repetição. Os dados mensurados foram submetidos ao teste de Hartley $(\mathrm{P}<0,05)$ e Lilliefors $(\mathrm{P}<0,05)$ previamente à análise de variância (ANOVA, $\mathrm{P}<0,05$ e $\mathrm{P}<0,01$ ), sendo as médias comparadas pelo teste de Tukey $(\mathrm{P}<0,05)$. Realizou-se análise de correlação de Pearson $(\mathrm{P}<0,01$ e $\mathrm{P}<0,05)$ das médias das temperaturas máximas, médias e mínimas com os dados biométricos.

Tabela 1 - Composição da solução nutritiva básica para a fertirrigação do minijardim clonal de Eucalyptus benthamii.

Table 1 - Composition of the basic nutrient solution for fertigation of the clonal mini-garden of Eucalyptus benthamii.

\begin{tabular}{|c|c|c|}
\hline \multicolumn{2}{|r|}{ Nutriente } & $\begin{array}{c}\text { Solução } \\
\text { nutritiva }^{*}\end{array}$ \\
\hline \multicolumn{3}{|c|}{$\left(\mathrm{mg} \mathrm{L}^{-1}\right)$} \\
\hline & $\mathrm{N}^{-} \mathrm{NO}^{3-}$ & 60,00 \\
\hline & $\mathrm{N}^{-} \mathrm{NH}^{4+}$ & 30,00 \\
\hline & $\mathrm{P}$ & 12,00 \\
\hline & $\mathrm{Ca}$ & 40,00 \\
\hline & $\mathrm{K}$ & 80,00 \\
\hline & S & 10,00 \\
\hline & $\mathrm{Mg}$ & 12,00 \\
\hline & $\mathrm{Cu}$ & 0,10 \\
\hline & $\mathrm{Fe}$ & 2,00 \\
\hline & Mo & 0,02 \\
\hline & $\mathrm{Mn}$ & 1,60 \\
\hline $\begin{array}{l}\text { Fonte de macro e } \\
\text { micronutriente }\end{array}$ & FQ / PM & $\left(\mathrm{mg} \mathrm{L}^{-1}\right)$ \\
\hline Nitrato de potássio & $\mathrm{KNO}_{3} / 101,10$ & 206,85 \\
\hline Monoamônio fostato & $\mathrm{NH}_{4} \mathrm{H}_{2} \mathrm{PO}_{4} / 115,03$ & 44,57 \\
\hline Nitrato de amônio & $\mathrm{NH}_{4} \mathrm{NO}_{3} / 80,04$ & 140,50 \\
\hline Cloreto de cálcio & $\mathrm{CaCl}_{2} \cdot 2 \mathrm{H}_{2} \mathrm{O} / 147,02$ & 111,13 \\
\hline Nitrato de cálcio & $\mathrm{Ca}\left(\mathrm{NO}_{3}\right)_{2} \cdot 4 \mathrm{H}_{2} \mathrm{O} / 236,15$ & 57,18 \\
\hline Cloreto de magnésio & $\mathrm{MgCl}_{2} \cdot 6 \mathrm{H}_{2} \mathrm{O} / 203,30$ & 50,46 \\
\hline Sulfato de magnésio & $\mathrm{MgSO}_{4} \cdot 7 \mathrm{H}_{2} \mathrm{O} / 246,48$ & 60,49 \\
\hline Sulfato de manganês & MnSO4.H2O / 169,01 & 4,9223 \\
\hline Sulfato de cobre & $\mathrm{CuSO}_{4} \cdot 5 \mathrm{H}_{2} \mathrm{O} / 249,68$ & 0,3929 \\
\hline Sulfato de ferro & $\mathrm{FeSO}_{4} \cdot 7 \mathrm{H}_{2} \mathrm{O} / 278,02$ & 9,9520 \\
\hline Sódio - EDTA & $\mathrm{Na}_{2}$-EDTA. $2 \mathrm{H}_{2} \mathrm{O} / 372,24$ & 13,3110 \\
\hline Molibdato de sódio & $\mathrm{Na}_{2} \mathrm{MoO}_{4} \cdot 2 \mathrm{H}_{2} \mathrm{O} / 241,95$ & 0,0504 \\
\hline
\end{tabular}

${ }^{\star} \mathrm{O}$ pH foi ajustado para 6,2 a $25^{\circ} \mathrm{C}$ com ácido clorídrico $(\mathrm{HCl})$ ou hidróxido de sódio $(\mathrm{NaOH})$, ambos a $1 \mathrm{M}$. FQ = fórmula química, $\mathrm{PM}$ = peso molecular. Fonte: Brondani et al. (2012).

Cerne, Lavras, v. 20, n. 1, p. 147-156, jul./set. 2014 


\section{RESULTADOS E DISCUSSÃO}

De acordo com a análise de variância houve interação significativa entre a coleta de brotações, clone, solução nutritiva e regulador de crescimento para a sobrevivência na saída da casa de vegetação ( $\mathrm{SCV}$ ), sobrevivência na saída da casa de sombra (SCS), enraizamento em área a pleno sol (EPS) e comprimento total do sistema radicial (CTSR) de miniestacas de Eucalyptus benthamii. A sobrevivência das miniestacas na saída da casa de vegetação (Tabela 2), sobrevivência na saída da casa de sombra (Tabela 3) e enraizamento das miniestacas em área de pleno sol (Tabela 4) apresentaram grande variabilidade de resposta.

Em termos gerais os valores da SCV foram elevados, sendo que a média foi de $90,8 \%$ (Tabela 2). Os índices da SCV para Eucalyptus benthamii podem ser considerados elevados para a miniestaquia de Eucalyptus (ALFENAS et al., 2004). Segundo Wendling e Xavier (2005) geralmente os índices de SCV são elevados devido às condições ambientais (como a luz, umidade e temperatura) serem controladas adequadamente para garantir a sobrevivência dos propágulos até a indução do enraizamento. Valores elevados da sobrevivência miniestacas de Eucalyptus na saída da casa de vegetação foram reportados em vários trabalhos, e geralmente situamse acima de $85 \%$, como o observado para $E$. grandis x $E$. globulus, E. urophylla $\mathrm{x}$ E. globulus (BORGES et al., 2011); $E$. grandis x E. urophylla (GOULART et al., 2010), E. cloeziana (ALMEIDA et al., 2007), E. grandis (TITON et al., 2003; WENDLING; XAVIER, 2005) e E. benthamii x $E$. dunnii (BRONDANI et al., 2010a; BRONDANI et al., 2010b).

Os valores da SCS foram reduzidos, denotando elevada sensibilidade das miniestacas de Eucalyptus benthamii às alterações ambientais (umidade relativa do ar, temperatura e irrigação) durante a fase de aclimatação (chegando a ocorrer mais de $85 \%$ de mortalidade). A média geral da SCS foi de $64,3 \%$ (Tabela 3). Geralmente, as maiores diferenças entre as espécies, variedades ou híbridos de Eucalyptus são mais pronunciadas durante a fase de aclimatação em casa de sombra, onde que os índices de sobrevivência podem variar de 0 a $100 \%$ (ALFENAS et al., 2004). Ao considerar as espécies de Eucalyptus subtropicais, as diferenças de enraizamento são ainda maiores, podendo ocorrer até a perda total do material (BRONDANI et al., 2010a; BRONDANI et al., 2010b; CORRÊA; FETT-NETO, 2004). O fato da elevada sensibilidade das miniestacas de $E$. benthamii durante o processo de aclimatação denota a necessidade do desenvolvimento de um novo tipo de manejo (tanto na casa de vegetação quanto na casa de sombra) para minimizar as perdas.

A porcentagem de enraizamento apresentou valores reduzidos (Tabela 4) ao comparar com os índices apresentados para outras espécies de Eucalyptus propagadas pela técnica de miniestaquia, tais como o E. grandis x E. urophylla (GOULART et al., 2010) e $E$. grandis (TITON et al., 2003; WENDLING; XAVIER, 2005). Em termos médios, a porcentagem de enraizamento foi de $43,5 \%$, sendo considerada uma espécie de difícil enraizamento. Apesar dos valores reduzidos de enraizamento, a média geral do CTSR foi de $125,0 \mathrm{~cm}$ e, as soluções S5 e S6 apresentaram os maiores valores para o CTSR (Tabela 5).

A correlação das temperaturas máximas, médias e mínimas com a SCV foi negativa, o que denota redução do enraizamento das miniestacas em casa de vegetação quando submetidas a elevadas temperaturas. O CTSR não apresentou correlação com os dados de temperatura da casa de vegetação, denotando pouca influência em termos da qualidade do sistema radicial (Tabela 6). Em termos gerais, a aplicação de AIB na concentração de $2.000 \mathrm{mg} \mathrm{L}^{-1}$ favoreceu a SCV, SCS, EPS e o CTSR para todos os materiais genéticos e as soluções S5 e S6 tenderam a favorecer os maiores valores de enraizamento. $\mathrm{O}$ pouco conhecimento a respeito dos fatores fisiológicos e ambientais que envolvem o enraizamento adventício em propágulos limitam a produção de mudas clonais de espécies florestais consideradas de difícil propagação.

A mortalidade das miniestacas de E. benthamii chegou a ser superior a $80 \%$ nas estações mais quentes, o que pode ser confirmado pela correlação negativa dos valores de temperatura com a sobrevivência durante a saída da casa de vegetação (Tabela 6), sendo esse comportamento semelhante ao observado para E. benthamii x E. dunnii (BRONDANI et al., 2010b). A elevada temperatura pode desnaturar enzimas, reduzir a absorção de nutrientes e alterar o metabolismo, o que prejudica o enraizamento adventício (CORRÊA; FETT-NETO, 2004), além de reduzir a capacidade morfogênica dos tecidos e favorecer a indução de calo na região basal (HARTMANN et al., 2011). A temperatura ótima para o enraizamento adventício varia entre as espécies, sendo alta para espécies tropicais e baixa para subtropicais (CORREAA; FETT-NETO, 2004). Além disso, a presença de AIB na concentração de 2.000 $\mathrm{mg} \mathrm{L}^{-1}$ apresentou acréscimos ao enraizamento adventício

Cerne, Lavras, v. 20, n. 1, p. 147-156, jul./set. 2014 
Tabela 2 - Valores médios da porcentagem de sobrevivência na saída da casa de vegetação (SCV) de miniestacas de Eucalyptus benthamii em relação aos tratamentos testados.

Table 2 - Average of survival percentage in greenhouse (SCV) of Eucalyptus benthamii mini-cuttings in relation to treatments.

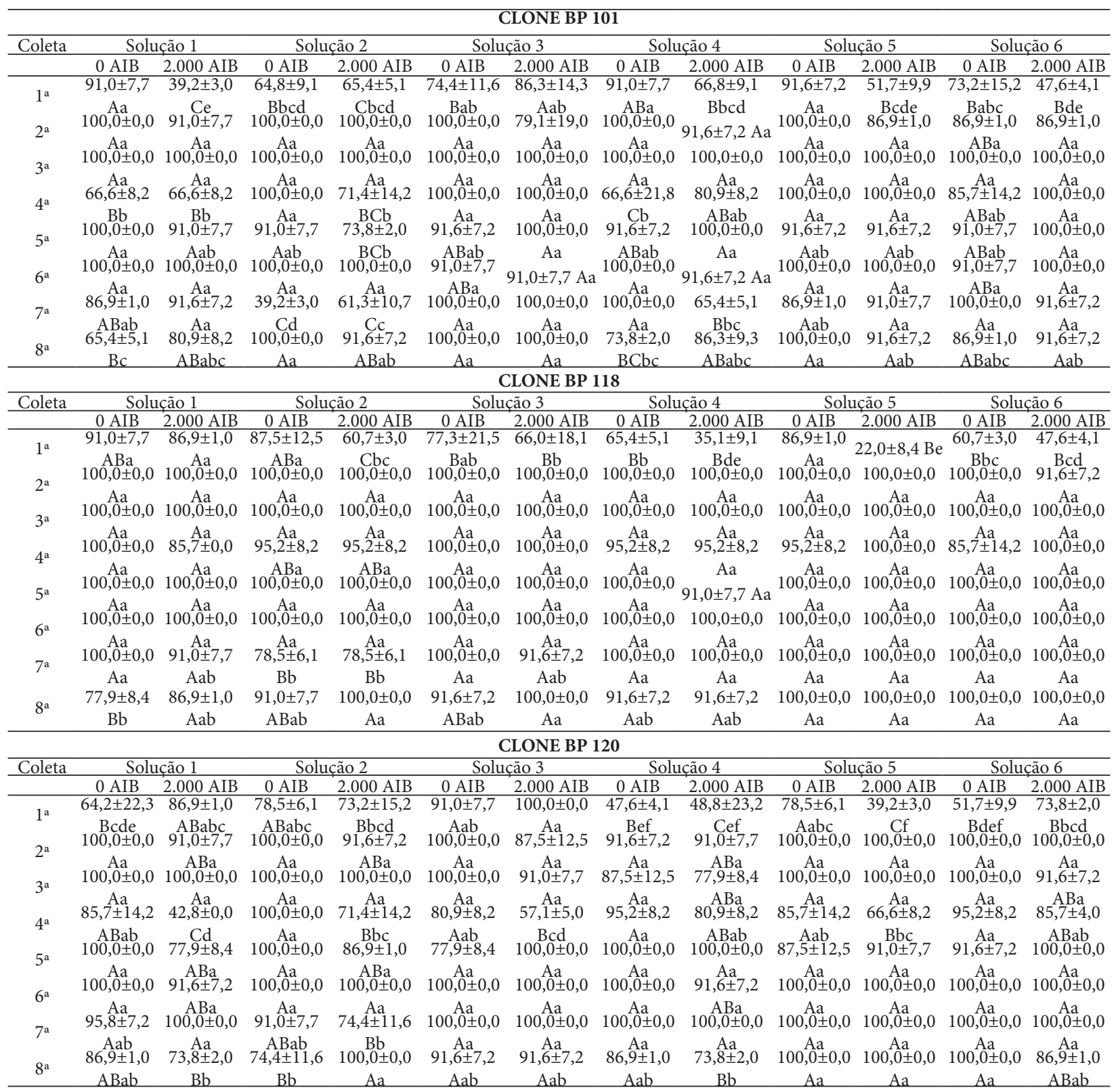

Nas colunas, médias seguidas por mesma letra maiúscula e, nas linhas, médias seguidas por mesma letra minúscula não diferem significativamente pelo teste de Tukey ao nível de 5\% de probabilidade de erro. $0 \mathrm{AIB}$ - isento de AIB $\left(0 \mathrm{mg} \mathrm{L}^{-1}\right), 2.000 \mathrm{AIB}$ - tratamento com AIB (2.000 mg L $\left.{ }^{-1}\right)$. Solução 1 - isento de Zn e B, Solução 2 - 0,5 mg L-1 de Zn, Solução 3 - 0,5 mg L ${ }^{-1}$ de B, Solução $4-0,5$ mg $\mathrm{L}^{-1}$ de Zn e B, Solução 5 - 1,0 mg L-1 de Zn e B, Solução 6 - 2,0 mg L L de Zn e B. Dados apresentados como: média \pm desvio padrão.

Cerne, Lavras, v. 20, n. 1, p. 147-156, jul./set. 2014 
Tabela 3 - Valores médios da porcentagem de sobrevivência na saída da casa de sombra (SCS) de miniestacas de Eucalyptus benthamii em relação aos tratamentos testados.

Table 3 - Average of survival percentage in shade-house (SCS) of Eucalyptus benthamii mini-cuttings in relation to treatments.

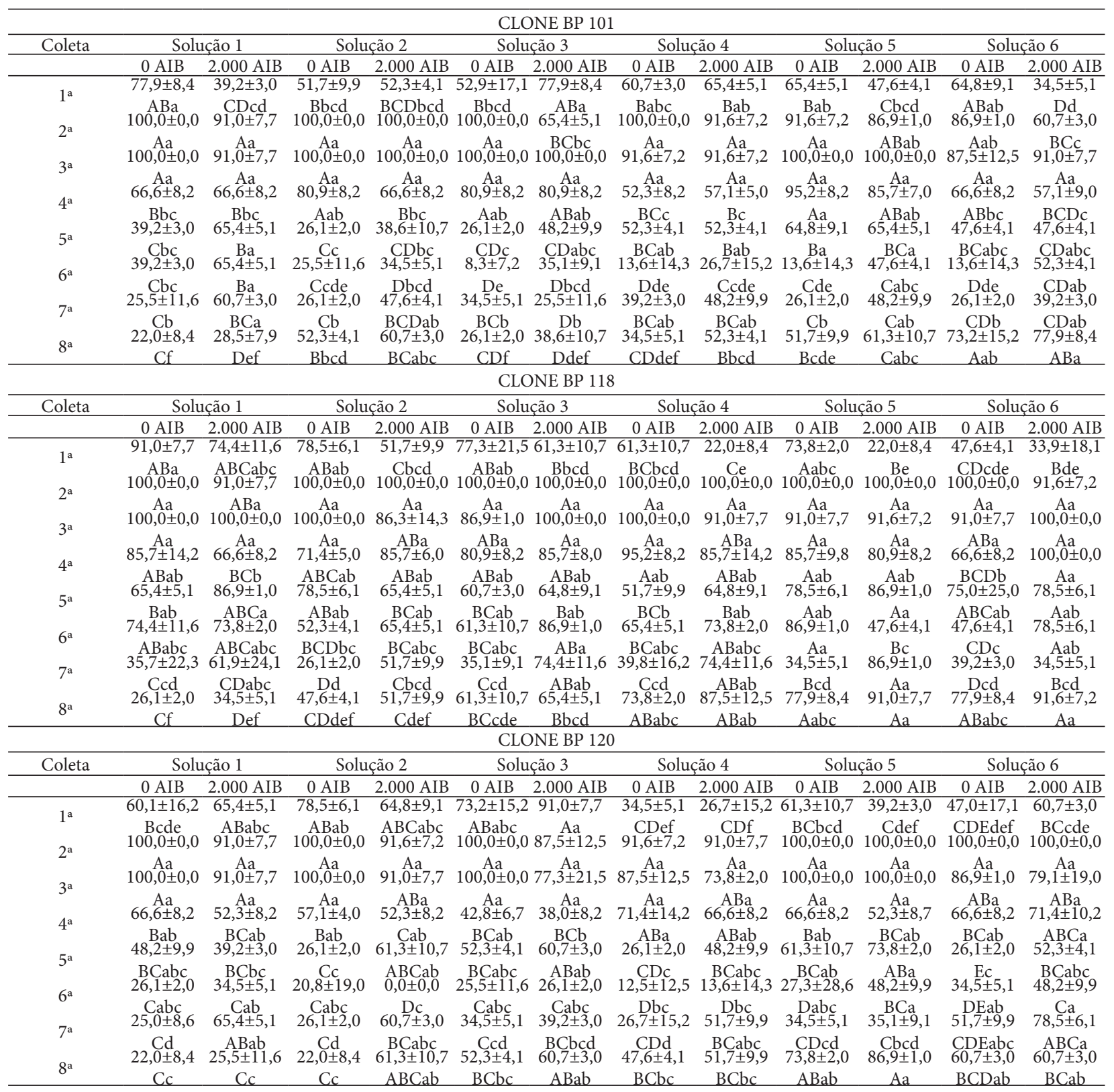

Nas colunas, médias seguidas por mesma letra maiúscula e, nas linhas, médias seguidas por mesma letra minúscula não diferem significativamente pelo teste de Tukey ao nível de $5 \%$ de probabilidade de erro. $0 \mathrm{AIB}$ - isento de AIB $\left(0 \mathrm{mg} \mathrm{L}^{-1}\right), 2.000 \mathrm{AIB}$ - tratamento com AIB (2.000 mg L L ${ }^{-1}$. Solução 1 - isento de Zn e B, Solução 2 - 0,5 mg L $\mathrm{L}^{-1} \mathrm{de} \mathrm{Zn}$, Solução 3 - 0,5 mg L $\mathrm{L}^{-1}$ de B, Solução 4 - 0,5 mg $\mathrm{L}^{-1}$ de Zn e B, Solução 5-1,0 mg L L de Zn e B, Solução 6 - 2,0 mg L $\mathrm{L}^{-1}$ de Zn e B. Dados apresentados como: média \pm desvio padrão.

Cerne, Lavras, v. 20, n. 1, p. 147-156, jul./set. 2014 
Tabela 4 - Valores médios da porcentagem de enraizamento em área a pleno sol (EPS) de miniestacas de Eucalyptus benthamii em relação aos tratamentos testados.

Table 4 - Average of adventitious rooting in area of full sun (EPS) of Eucalyptus benthamii mini-cuttings in relation to treatments.

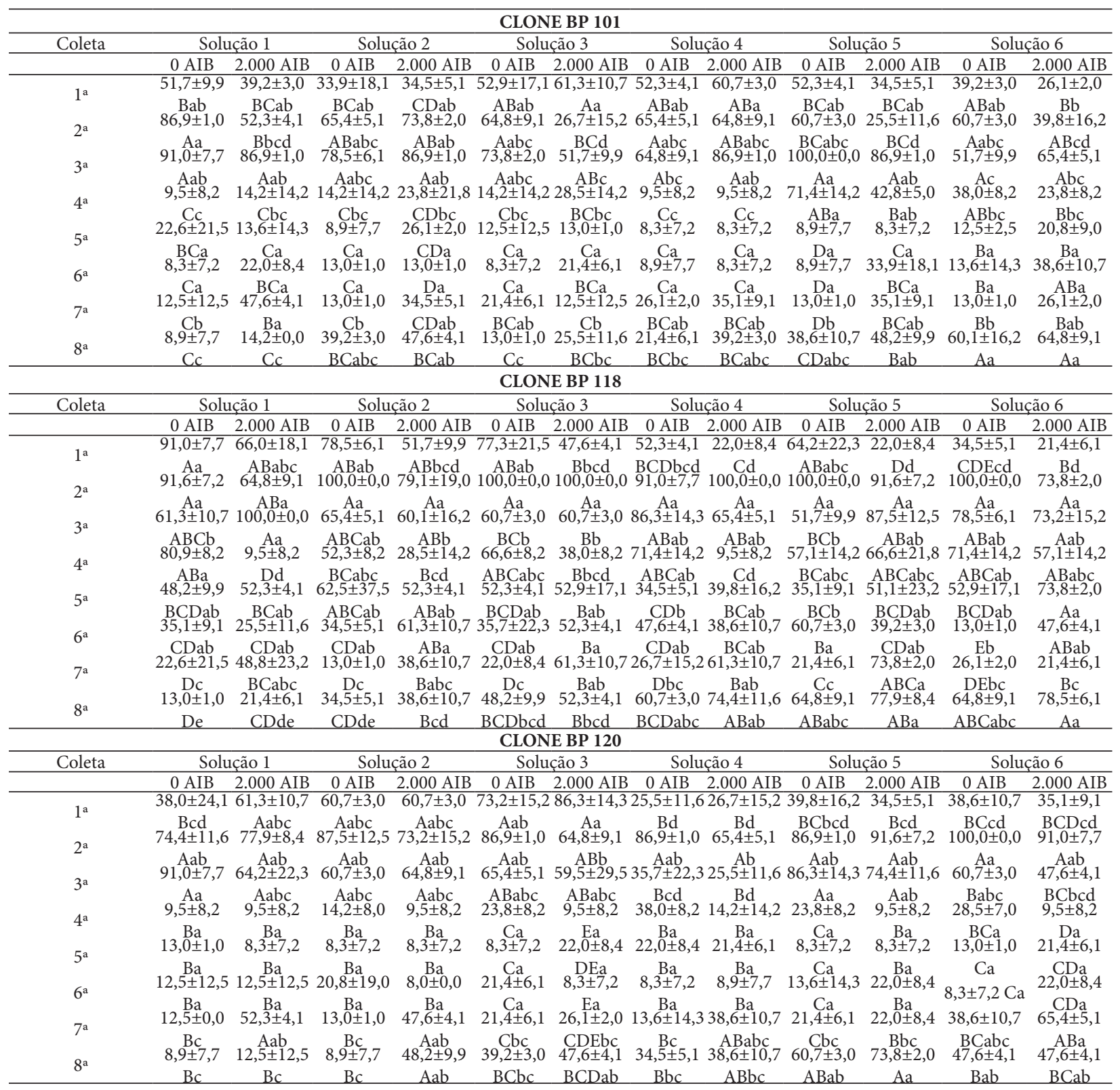

Nas colunas, médias seguidas por mesma letra maiúscula e, nas linhas, médias seguidas por mesma letra minúscula não diferem significativamente pelo teste de Tukey ao nível de $5 \%$ de probabilidade de erro. 0 AIB - isento de AIB $\left(0 \mathrm{mg} \mathrm{L}^{-1}\right), 2.000$ AIB - tratamento com AIB (2.000 $\left.\mathrm{mg} \mathrm{L}^{-1}\right)$. Solução 1 - isento de Zn e B, Solução 2 - 0,5 mg L-1 de Zn, Solução 3 - 0,5 mg L ${ }^{-1}$ de B, Solução 4 - 0,5 mg $\mathrm{L}^{-1}$ de Zn e B, Solução 5 - 1,0 mg L L de Zn e B, Solução 6 - 2,0 mg L $\mathrm{L}^{-1}$ de Zn e B. Dados apresentados como: média \pm desvio padrão.

Cerne, Lavras, v. 20, n. 1, p. 147-156, jul./set. 2014 
Tabela 5 - Valores médios do comprimento total do sistema radicial (CTSR - cm) de miniestacas de Eucalyptus benthamii em relação aos tratamentos testados.

Table 5 - Average of total length of the adventitious root system (CTSR - cm) of Eucalyptus benthamii mini-cuttings in relation to treatments.

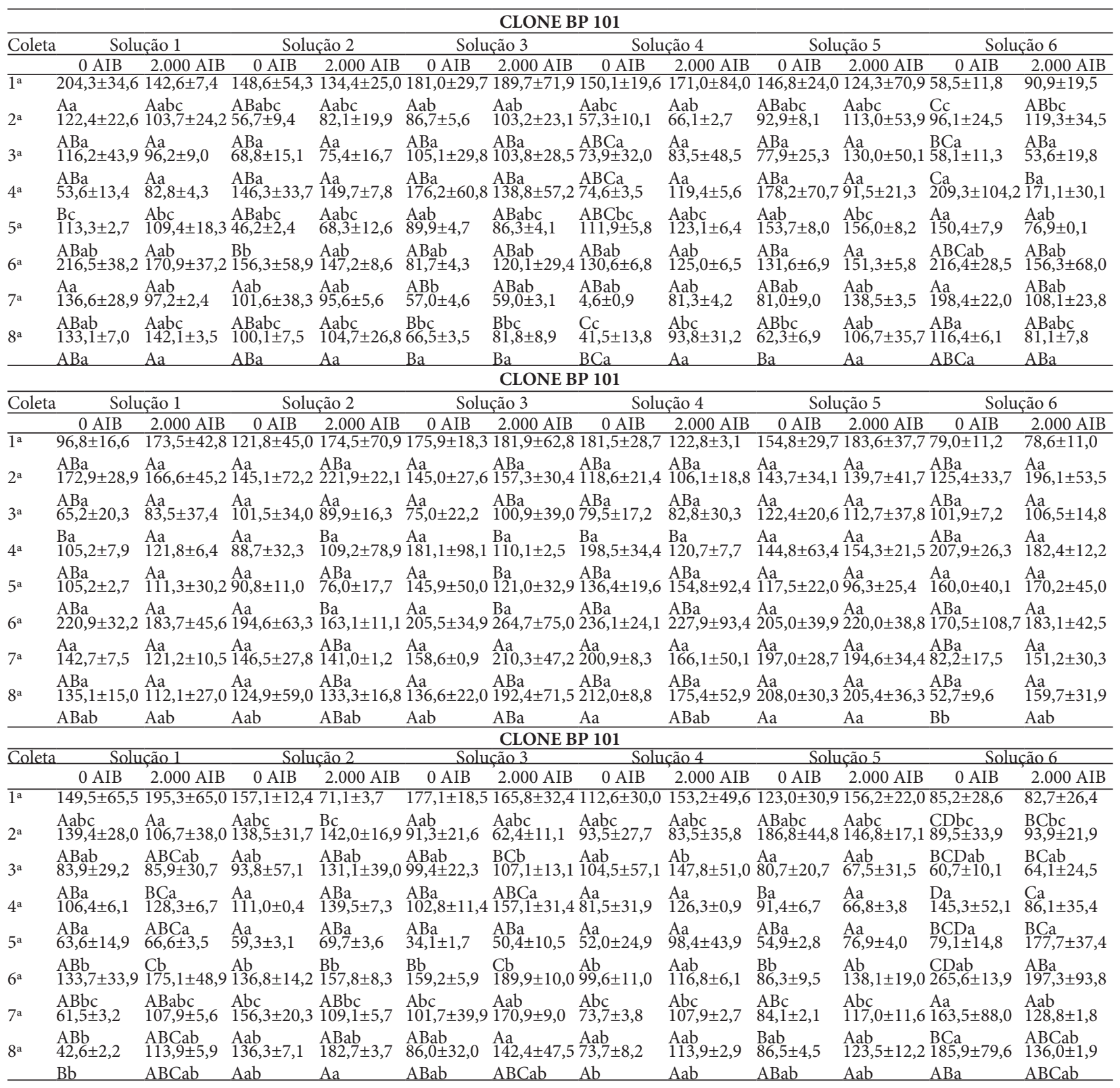

Nas colunas, médias seguidas por mesma letra maiúscula e, nas linhas, médias seguidas por mesma letra minúscula não diferem significativamente pelo teste de Tukey ao nível de $5 \%$ de probabilidade de erro. $0 \mathrm{AIB}$ - isento de AIB $\left(0 \mathrm{mg} \mathrm{L}^{-1}\right), 2.000 \mathrm{AIB}$ - tratamento com AIB (2.000 mg L $\left.{ }^{-1}\right)$. Solução 1 - isento de Zn e B, Solução 2 - 0,5 mg L-1 de Zn, Solução 3 - 0,5 mg L ${ }^{-1}$ de B, Solução 4 - 0,5 mg $\mathrm{L}^{-1}$ de Zn e B, Solução 5 - 1,0 mg L L de Zn e B, Solução 6 - 2,0 mg L $\mathrm{L}^{-1}$ de Zn e B. Dados apresentados como: média \pm desvio padrão.

Cerne, Lavras, v. 20, n. 1, p. 147-156, jul./set. 2014 
Tabela 6 - Resumo da Matriz de Correlação de Pearson para a temperatura do ar máxima (TMAX), temperatura média (TMED), temperatura mínima (TMIN), sobrevivência durante a saída da casa de vegetação (SCV), sobrevivência durante a saída da casa de sombra (SCS), enraizamento em área a pleno sol (EPS) e comprimento total do sistema radicial (CTSR) de miniestacas de Eucalyptus benthamii.

Table 6 - Summary of Pearson Correlation Matrix for the maximum air temperature (TMAX), mean temperature (TMED), minimum temperature (TMIN), survival in greenhouse (SCV), survival in shade-house (SCS), rooting in the area in full sun (EPS) and total length of the adventitious root system (CTSR) of Eucalyptus benthamii mini-cuttings.

\begin{tabular}{|c|c|c|c|c|c|c|c|}
\hline Variável & TMAX & TMED & TMIN & SCV & SCS & EPS & CTSR \\
\hline TMAX & 1 & & & & & & \\
\hline TMED & $0,97^{\star *}$ & 1 & & & & & \\
\hline TMIN & $0,93^{\star *}$ & $0,99^{* *}$ & 1 & & & & \\
\hline SCV & $-0,29^{* *}$ & $-0,30^{* *}$ & $-0,30^{\star *}$ & 1 & & & \\
\hline SCS & $0,49^{\star *}$ & $0,48^{\star \star}$ & $0,47^{\star \star}$ & $0,35^{\star}$ & 1 & & \\
\hline EPS & $0,52^{\star *}$ & $0,55^{\star *}$ & $0,55^{\star *}$ & $0,28^{\star}$ & $0,80^{\star *}$ & & \\
\hline CTSR & $-0,03^{\mathrm{ns}}$ & $-0,06^{\mathrm{ns}}$ & $-0,07^{\mathrm{ns}}$ & $0,04^{\mathrm{n}}$ & $-0,01^{\mathrm{ns}}$ & $0,04^{\mathrm{ns}}$ & 1 \\
\hline
\end{tabular}

${ }^{\text {ns }}$ Valor não significativo ao nível de $5 \%$ de probabilidade de erro, pelo teste $\mathrm{F}$. ${ }^{\star *}$ Valor significativo ao nível de $1 \%$ de probabilidade de erro, pelo teste $\mathrm{F}$.

das miniestacas de $E$. benthamii, sendo que o seu efeito indutivo ficou condicionado as concentrações de $\mathrm{Zn}$ e $\mathrm{B}$ das soluções nutritivas que interferiram na qualidade nutricional da miniestaca, corroborando as observações de Schwambach et al. (2005) ao avaliarem o enraizamento de microestacas E. globulus.

De acordo com as observações de Schwambach et al. (2005) a deficiência de $\mathrm{Zn}$ pode ter reduzido a biossíntese de triptofano, e dessa forma, influenciado a redução dos teores endógenos das auxinas, dificultando o enraizamento das microestacas. Essa hipótese está de acordo no que tange a correlação do estado nutricional do propágulo com o aumento dos índices de enraizamento pela aplicação de regulador de crescimento (CUNHA et al., 2009; SCHWAMBACH et al., 2005). Sabe-se que o Zn é requerido para síntese de triptofano (POLLMANN et al., 2009) e as concentrações adequadas desse microelemento na miniestaca pode ter favorecido a síntese de auxinas endógenas promovendo a rizogênese nas miniestacas de E. benthamii. Esses resultados sugerem que os efeitos do AIB em nível morfogenético também estão associados aos aspectos nutricionais que as minicepas são condicionadas em sistemas de minijardins clonais, regulando a indução da formação de calo e/ou de raiz adventícia.

\section{CONCLUSÕES}

O enraizamento adventício em miniestacas de Eucalyptus benthamii dependeu do material genético, da coleta de brotações, da aplicação de AIB e concentrações de $\mathrm{Zn}$ e B. Os valores da porcentagem de enraizamento de Eucalyptus benthamii foram baixos, sendo os materiais genéticos considerados de difícil propagação pela miniestaquia. As miniestacas obtidas de minicepas que receberam as soluções nutritivas $\mathrm{S} 5\left(1,0 \mathrm{mg} \mathrm{L}^{-1} \mathrm{de} Z \mathrm{Zn} \mathrm{e} \mathrm{B}\right)$ e S6 (2,0 $\mathrm{mg} \mathrm{L}^{-1}$ de $\mathrm{Zn}$ e B) associadas a presença de AIB na concentração de $2.000 \mathrm{mg} \mathrm{L}^{-1}$ apresentaram os maiores índices de enraizamento.

\section{AGRADECIMENTOS}

Os autores agradecem agradecemos à FAPESP, CAPES e Planflora Mudas Florestais pelo apoio concedido.

\section{REFERÊNCIAS}

ALFENAS, A.C.; ZAUZA, E.A.V.; MAFIA, R.G.; ASSIS, T.F. Clonagem e doenças do eucalipto.Viçosa: Editora UFV, 2004. 442p.

ALMEIDA, F.D.; XAVIER, A.; DIAS, J.M.M.; PAIVA, H.N. Eficiência das auxinas (AIB e ANA) no enraizamento de miniestacas de clones de Eucalyptus cloeziana F. Muell. Revista Árvore, Viçosa, v.31, n.3, p.455-463, 2007.

BORGES, S.R.; XAVIER, A.; OLIVEIRA, L.S.; MELO, L.A.; ROSADO, A.M. Enraizamento de miniestacas de clones híbridos de Eucalyptus globulus. Revista Árvore, Viçosa, v.35, n.3, p.425-434, 2011.

BRONDANI, G.E.; BACCARIN, F.J.B.; WIT ONDAS, H.W.; GONÇALVES, A.N.; ALMEIDA, M. Avaliação morfofisiológica e produção de minijardim clonal de Eucalyptus benthamii em relação a Zn e B. Pesquisa Florestal Brasileira, Colombo, v.32, n.70, p.151-164, 2012.

BRONDANI, G.E.; GROSSI, F.; WENDLING, I.; DUTRA, L.F.; ARAUJO, M.A. Aplicação de IBA para o enraizamento de miniestacas de Eucalyptus benthamii Maiden \& Cambage x Eucalyptus dunnii Maiden. Acta Scientiarum. Agronomy, Maringá, v.32, n.4, p.667674, 2010a.

Cerne, Lavras, v. 20, n. 1, p. 147-156, jul./set. 2014 
BRONDANI, G.E.; WENDLING, I.; GROSSI, F.; DUTRA, L.F.; ARAUJO, M.A. Miniestaquia de Eucalyptus benthamii $\times$ Eucalyptus dunnii: (II) sobrevivência e enraizamento de miniestacas em função das coletas e estações do ano. Ciência Florestal, Santa Maria, v.20, n.3, p.453-465, 2010 b.

CORREAA, L.R.; FETT-NETO, A.G. Effects of temperature on adventitious root development in microcuttings of Eucalyptus saligna Smith and Eucalyptus globulus Labill. Journal of Thermal Biology, Durham, v.29, n.6, p.315-324, 2004.

CUNHA, A.C.M.C.M.; PAIVA, H.N.; LEITE, H.G.; BARROS, N.F.; LEITE, F.P. Influência do estado nutricional de minicepas no enraizamento de miniestacas de eucalipto. Revista Árvore, Viçosa, v.33, n.4, p.607$615,2009$.

CUNHA, A.C.M.C.M.; WENDLING, I.; SOUZA JUNIOR, L. Produtividade e sobrevivência de minicepas de Eucalyptus benthamii Maiden et Cambage em sistema de hidroponia e em tubete. Ciência Florestal, Santa Maria, v.15, n.3, p.307-310, 2005.

DIAS, P.C.; OLIVEIRA, L.S.; XAVIER, A.; WENDLING, I. Estaquia e miniestaquia de espécies florestais lenhosas do Brasil. Pesquisa Florestal Brasileira, Colombo, v.32, n.72, p.453-462, 2012.

EMBRAPA. Empresa Brasileira de Pesquisa Agropecuária. Programa SIARCS - sistema integrado para análise de raízes e cobertura do solo: versão 3.0. São Carlos: Embrapa Instrumentação Agropecuária, 1996.

GOULART, P.B.; XAVIER, A.; DIAS, J.M.M. Efeito de antioxidantes no enraizamento de miniestacas de clones de Eucalyptus grandis x E. urophylla. Revista Árvore, Viçosa, v.34, n.6, p.961-972, 2010.

GRAÇA, M.E.C.; SHIMIZU, J.Y.; TAVARES, F.R. Capacidade de rebrota e de enraizamento de Eucalyptus benthamii. Boletim de Pesquisa Florestal, Colombo, n.39, p.135-138, 1999.

HARTMANN, H.T.; KESTER, D.E.; DAVIES JR, F.T.; GENEVE, R.L. Plant propagation: principles and practices. 8.ed. São Paulo: Prentice-Hall, 2011. 915p.

HIGASHI, E.N.; SILVEIRA, R.L.V.A.; GONÇALVES, A.N. Nutrição e adubação em minijardim clonal

Cerne, Lavras, v. 20, n. 1, p. 147-156, jul./set. 2014 hidropônico de Eucalyptus. Instituto de Pesquisas e Estudos Florestais, 2002. 21p. (IPEF. Circular Técnica, 194).

POLLMANN, S.; DÜCHTING, P.; WEILER, E.W. Tryptophan-dependent indole-3-acetic acid biosynthesis by 'IAA-synthase' proceeds via indole-3-acetamide. Phytochemistry, Elmsford, v.70, n.4, p.523-531, 2009. DOI: 10.1016/j.phytochem.2009.01.021

\section{SCHWAMBACH, J.; FADANELLI, C.; FETT-NETO,} A.G. Mineral nutrition and adventitious rooting in microcuttings of Eucalyptus globulus. Tree Physiology, Victoria, v.25, n.4, p.487-494, 2005.

TITON, M.; XAVIER, A.; OTONI, W.C.; REIS, G.G. Efeito do AIB no enraizamento de miniestacas e microestacas de clones de Eucalyptus grandis W. Hill ex Maiden. Revista Árvore, Viçosa, v.27, n.1, p.1-7, 2003.

TRUEMAN, S.J.; ADKINS, M.F. Effect of aminoethoxyvinylglycine and 1-methylcyclopropene on leaf abscission and root formation in Corymbia and Eucalyptus cuttings. Scientia Horticulturae, Amsterdam, v.161, p.1-7, 2013.

WENDLING, I.; XAVIER, A. Influência do ácido indolbutírico e da miniestaquia seriada no enraizamento e vigor de miniestacas de clones de Eucalyptus grandis. Revista Árvore, Viçosa, v.29, n.6, p.921-930, 2005.

WENDLING, I.; XAVIER, A.; GOMES, J.M.; PIRES, I.E.; ANDRADE, H.B. Efeito do regulador de crescimento AIB na propagação de clones de Eucalyptus spp. por miniestaquia. Revista Árvore, Viçosa, v.24, n.2, p.187-192, 2000.

$\overline{\text { Recebido: } 25 \text { de novembro de 2011; aceito: } 21 \text { de agosto de } 2013 .}$ 